\title{
Analysis on the Regularity Features of Extraordinarily Serious Work Safety Accidents in China
}

\author{
Zequan $\mathrm{Li}^{1, \text { a, * }}$, Yingying Wang ${ }^{2, b}$ \\ ${ }^{1}$ Institute of Information Research, State Administration of Work Safety, Beijing, 100029, China \\ ${ }^{2}$ College of Resources and Safety Engineering, China University of Ming and Technology,Beijing,100083, \\ China \\ alizequan066@163.com, b89373038@qq.com \\ *corresponding author
}

Keywords: Work safety, extraordinarily serious accidents, accident regularity.

\begin{abstract}
Based on the statistical analysis of 141 extraordinarily serious accidents from 2001 to 2015, the regularity of occurrence is generalized for extraordinarily serious accidents in China. Also, the features of extraordinarily serious accidents are analyzed in terms of time distribution, regional distribution, key industrial sectors, urban functional areas, and crowded places, etc. The findings are of great value to the prevention of extraordinarily serious accidents.
\end{abstract}

\section{Introduction}

Since the arrival of the 21st century, China has maintained the rapid and healthy development of economy and society. The gross national product (GDP) increased from 10.87 trillion RMB in 2017 to 67.67 trillion RMB in 2015, up 269.6\%; the gross value of industrial output went up $292.6 \%$ from 4.35 trillion RMB to 22.9 trillion RMB; the percentage of urban population reached 56.1\% after a growth of 18.4 percentage points from $37.7 \%$; the mileage of roads increased by $169.6 \%$ from 1.698 million kilometers to 4.5773 million kilometers; and the number of private cars increased from 18.02 million to 172.28 million, up 856\%.

While making world-acknowledged achievements in economic development, new progresses have been constantly achieved in the field of work safety [1-3]. The number of work safety accidents and number of deaths caused thereby in China decreased from 1.001 million and 130,000 in 2001 to 263,000 and 64,000 in 2015, down 73.8\% and 50.8\% respectively; and the number of extraordinarily serious accidents and number of deaths caused thereby were lowered from 15 and 688 respectively in 2001 to 6 and 302 respectively in 2015, down 60.0\% and 54.8\% respectively [45].

Meanwhile, the situation of work safety is still complicated in recent years due to the frequent occurrence of unexpected accidents. The main reasons and regularity features are therefore generalized from 141 extraordinarily serious accidents occurred since 2001 to provide the reference for decisions on how to avoid accidents in the future.

\section{General Condition of Extraordinarily Serious Accidents in China from 2001 to 2015}

From 2001 to 2015, 141 extraordinarily serious work safety accidents occurred in China, involving such key industrial sectors as coal mine, ferrous \& nonferrous, dangerous chemicals, fireworks, fire, building construction, road traffic, railway traffic, water traffic and air traffic, and caused 7,347 deaths in total. On average, there were 9.4 accidents and 489.8 deaths per year, and each extraordinarily serious accident led to 52.1 deaths. The details are given in Table 1.

Ever since 2001, the extraordinarily serious accidents in China had showed a trend of increase and decrease in three periods on the whole, as given in Fig. 1. Since China entered the World Trade Organization in 2001, the Chinese economy had maintained a highly extensive growth rate of more 
than $10 \%$, and enterprises had kept engaging in illegal work and overcapacity production, pushing up the number of extraordinarily serious accidents year by year. Among them, the year of 2005 marked a peak for the largest number of extraordinarily serious accidents, that is, 17 accidents, which caused the death of 1,200 people. During the "Eleventh Five-year Plan" period, the number of extraordinarily serious accidents decreased dramatically, especially only 5 in 2009, but the number fluctuated significantly in several years including 2008 and 2010, due to the noticeable increase of investments in fixed assets and the accelerating construction of cities and large projects. During the "Twelfth Five-year Plan" period, the number of extraordinarily serious accidents in China was stabilized to be lower than 6. Especially, there were only 2 extraordinarily serious accidents in 2012, and 6 accidents causing 302 deaths in 2015, down $64.7 \%$ and $74.8 \%$ respectively compared with the peak in 2005.

Table 1 Extraordinarily Serious Accidents in Key Industrial Sectors of China from 2001 to 2015

\begin{tabular}{c|c|c|c|c|c}
\hline Industry & Deaths & $\begin{array}{c}\text { Percentage } \\
\text { of Deaths }\end{array}$ & $\begin{array}{c}\text { Number of } \\
\text { Accidents }\end{array}$ & $\begin{array}{c}\text { Percentage of } \\
\text { Accidents }\end{array}$ & $\begin{array}{c}\text { Average Number of Deaths Per } \\
\text { Occurrence }\end{array}$ \\
\hline Railway Traffic & 112 & $1.5 \%$ & 2 & $1.4 \%$ & 56.0 \\
\hline $\begin{array}{c}\text { Building } \\
\text { Construction }\end{array}$ & 143 & $1.9 \%$ & 3 & $2.1 \%$ & 47.7 \\
\hline Fireworks & 151 & $2.1 \%$ & 4 & $2.8 \%$ & 14.5 \\
\hline $\begin{array}{c}\text { Dangerous } \\
\text { Chemicals }\end{array}$ & 174 & $2.4 \%$ & 12 & $8.5 \%$ & 76.0 \\
\hline Air Traffic & 228 & $3.1 \%$ & 3 & $2.1 \%$ & 46.7 \\
\hline Water Traffic & 280 & $3.8 \%$ & 6 & $4.3 \%$ & 46.7 \\
\hline Fire & 420 & $5.7 \%$ & 9 & $6.4 \%$ & 64.4 \\
\hline Others & 515 & $7.0 \%$ & 8 & $5.7 \%$ & 38.7 \\
\hline Road Traffic & 697 & $9.5 \%$ & 18 & $12.8 \%$ & 113.6 \\
\hline $\begin{array}{c}\text { Ferrous \& } \\
\text { Nonferrous }\end{array}$ & 795 & $10.8 \%$ & 7 & $5.0 \%$ & 55.5 \\
\hline Coal Mine & 3832 & $52.2 \%$ & 69 & $48.9 \%$ & 52.1 \\
\hline Total & 7347 & $100 \%$ & 141 & $100 \%$ & \\
\hline
\end{tabular}

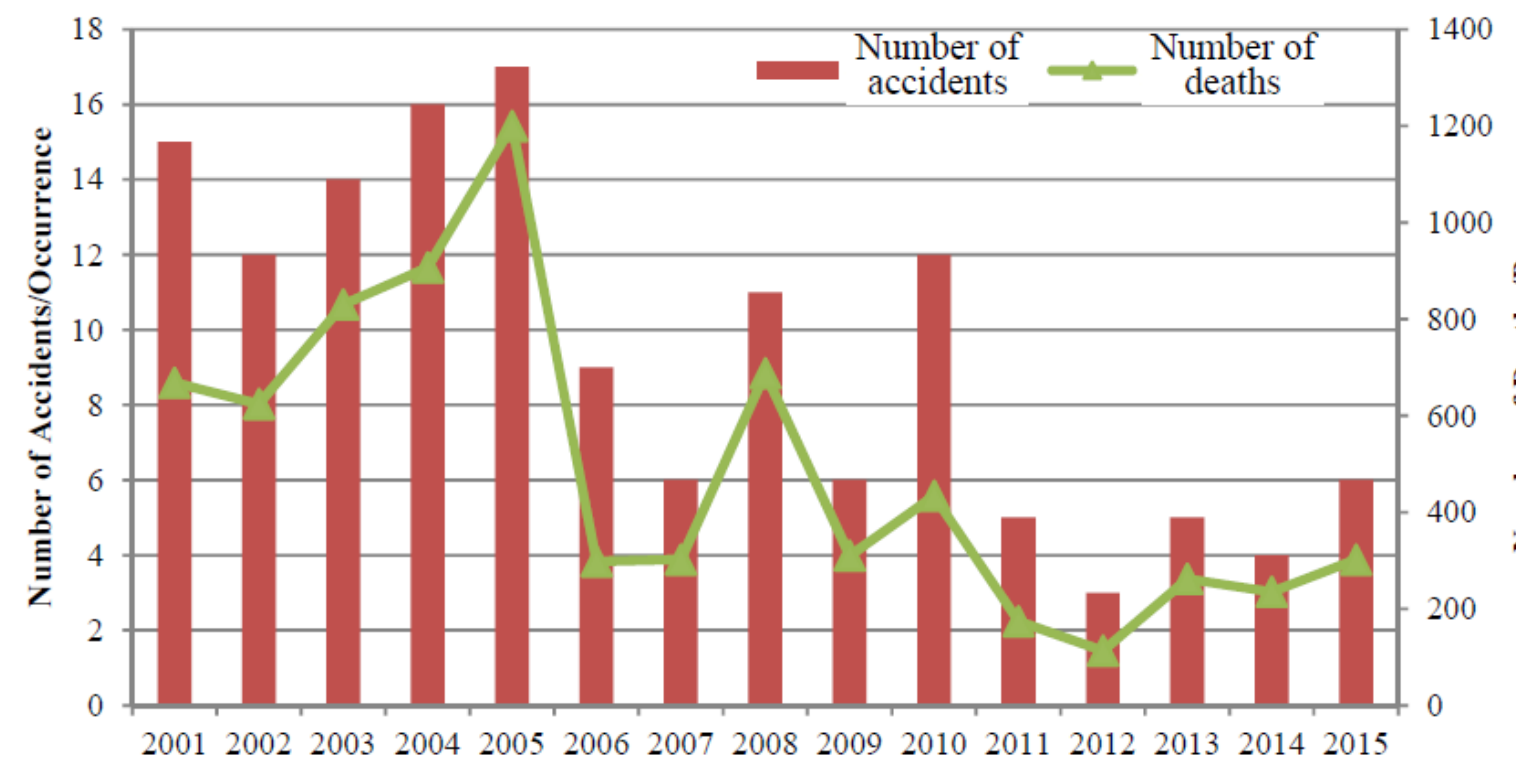

Fig. 1 Change Trend of Extraordinarily Serious Accidents from 2001 to 2015 


\section{Extraordinarily Serious Accidents in Key Industrial Sectors}

\subsection{Change Trend of Extraordinarily Serious Accidents in Coal Mine}

In 2001-2005, China faced the short supply of coal due to the rapid economic development, so overcapacity and illegal coal mining existed and often caused accidents. Within the five years, 42 extraordinarily serious accidents occurred and killed 2,595 persons, including 7 accidents with more than 100 deaths each, and 1,052 deaths in total. In 2005, 4 accidents caused more than 100 deaths each, and 614 deaths in total, resulting in very adverse social effects. After 2006, the work safety of coal mine in China was improving steadily with the considerable decrease of extraordinarily serious accidents in coal mine. Especially in 2014 and 2015, there was not any extraordinarily serious accident in coal mine. The change trend of extraordinarily serious accidents in coal mine is presented in Fig. 2.

\subsection{Change Trend of Extraordinarily Serious Accidents in Road Traffic}

Ever since 2001, the number of extraordinarily serious accidents in road traffic was fluctuating downwards. During the "Tenth Five-year Plan” period, there were 9 accidents causing 338 deaths. During the "Eleventh Five-year Plan" period, the number of extraordinarily serious accidents in road traffic decreased dramatically in China. There were only 3 accidents causing 114 deaths in total during the five years. During the "Twelfth Five-year Plan" period, the work safety in road traffic of China was obviously improving, and especially the number of extraordinarily serious accidents in road traffic was stabilizing. During the period, there were totally 6 extraordinarily serious accidents and 245 deaths. The change trend of extraordinarily serious accidents in road traffic was as shown in Fig. 3.

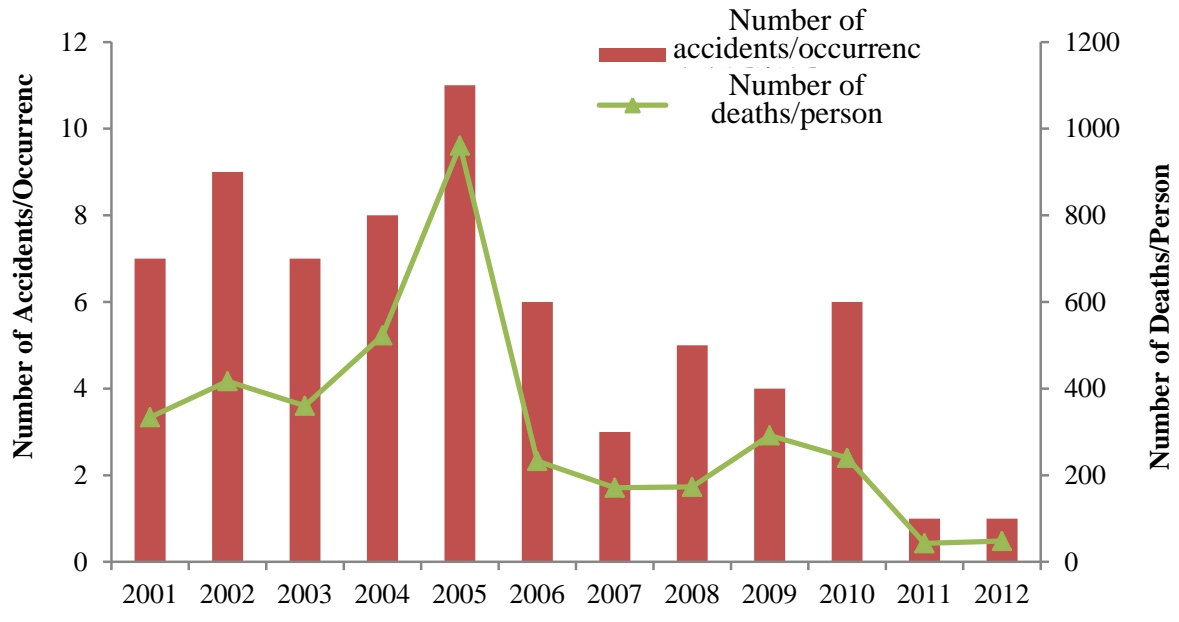

Fig. 2 Change Trend of Extraordinarily Serious Accidents in Coal Mine

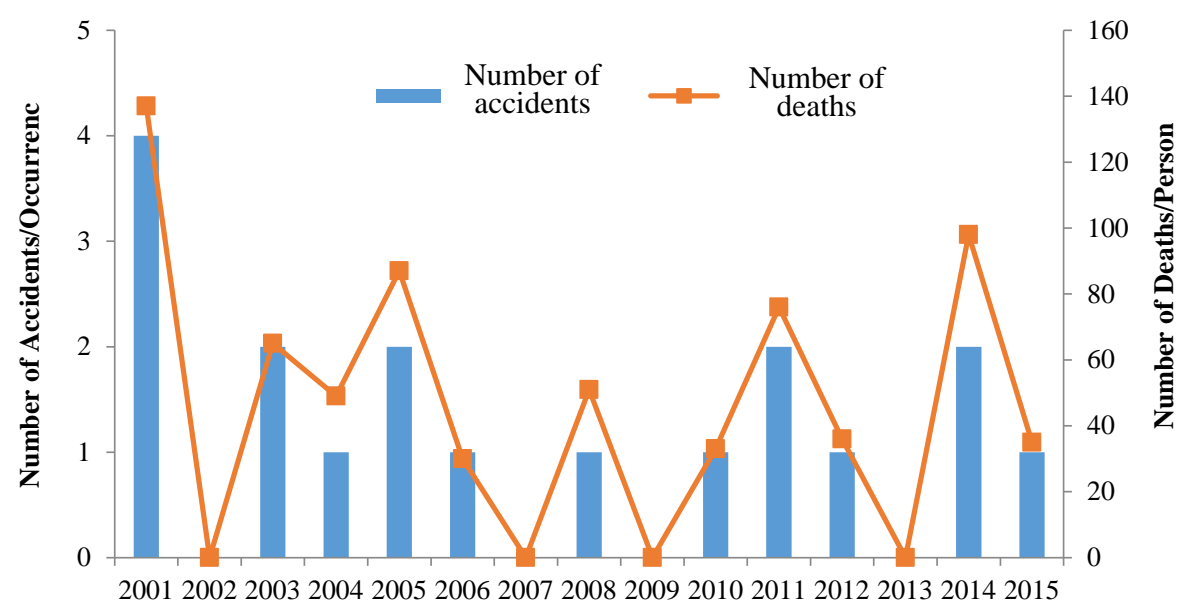

Fig. 3 Change Trend of Extraordinarily Serious Accidents in Road Traffic 


\subsection{Change Trend of Extraordinarily Serious Accidents in Ferrous \& Nonferrous Mine}

During the "Tenth Five-year Plan" period, the safety basis for ferrous \& nonferrous mine in China was weak, and the illegal mining kept happening. Especially, extraordinarily serious accidents often occurred at the rate of one occurrence per year. During the "Eleventh Five-year Plan" period, the extraordinarily serious accidents were effectively controlled in ferrous \& nonferrous mine by promoting the advanced and applicable technologies including deep hole blasting, mechanical shoving, and secondary mechanical crushing, etc. No extraordinarily serious accident occurred in the period except 2008.

\section{Analysis on Regularity Features of Extraordinarily Serious Accidents}

Extraordinarily serious accidents may seem to occur occasionally, but they are actually subject to internal mechanism and inherent regularity. To effectively control extraordinarily serious accidents, it is necessary to first understand its regularity features. After analyzing 141 extraordinarily serious accidents, the following regularity features are found:

(1) Extraordinarily serious accidents showed a fluctuating but decreasing trend on the whole

As revealed in the general trend of accidents, the number of extraordinarily serious accidents kept a trend of decrease in China since 2006, but it fluctuated more in several years. In 2008, 2010 and 2013, the number bounced up, up $83.3 \%, 120 \%$ and $100 \%$ respectively compared with the previous year. This reveals the occasional, repetitive and fluctuating nature of extraordinarily serious accidents.

(2) Extraordinarily serious accidents frequently occurred in summers and winters

As it often rained in summers, road traffic accidents were easily caused. When the increasing demand for coal urged the illegal and overcapacity mining, extraordinarily serious accidents often occurred in July and August, that is, 17 accidents and 16 accidents respectively, accounting for 23.4\% of total accidents. In winters, road traffic accidents were often caused by the frozen surface, while most industrial and mining enterprises worked extra time to catch up with the schedule at the yearend, so many extraordinarily serious accidents occurred in November and December, that is, 19 accidents and 13 accidents respectively, accounting for $22.7 \%$ of total accidents. The findings are presented in Fig. 4.

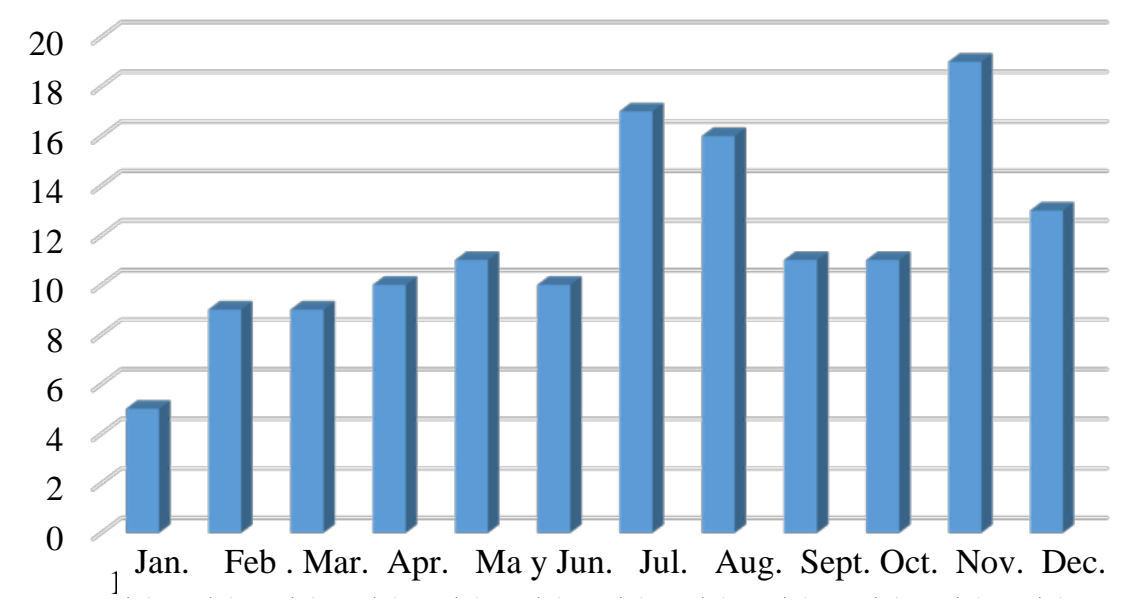

Fig. 4 Analysis on Extraordinarily Serious Accidents by Month from 2001 to 2015

(3) Extraordinarily serious accidents occurred mostly in the day

The production and operation activities mainly happened in the day, so extraordinarily serious accidents mostly occurred at 6:00-12:00 in the morning, which was followed by 12:00-18:00 in the afternoon. There were 48 and 42 accidents in such two time periods respectively, accounting for 63.8\% of total accidents, as shown in Fig. 5. 

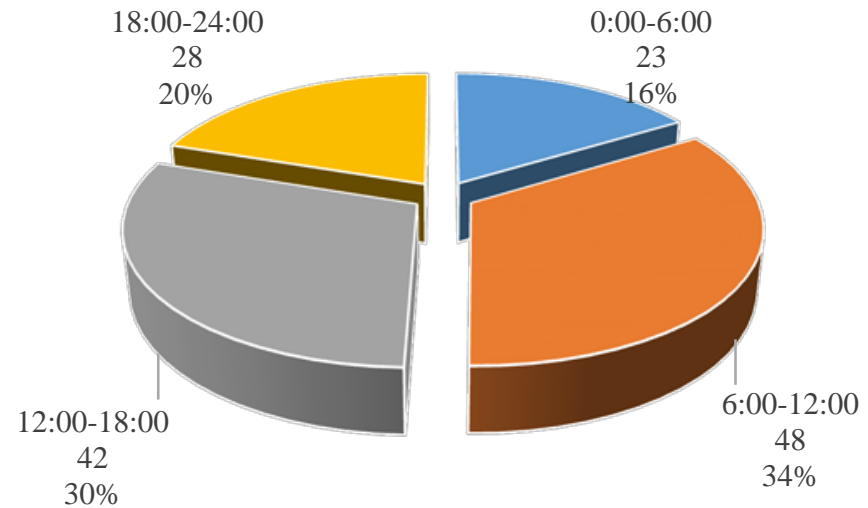

Fig. 5 Analysis on Extraordinarily Serious Accidents by Time Period from 2001 to 2015 (4) Extraordinarily serious accidents mainly occurred in coal mine and road traffic

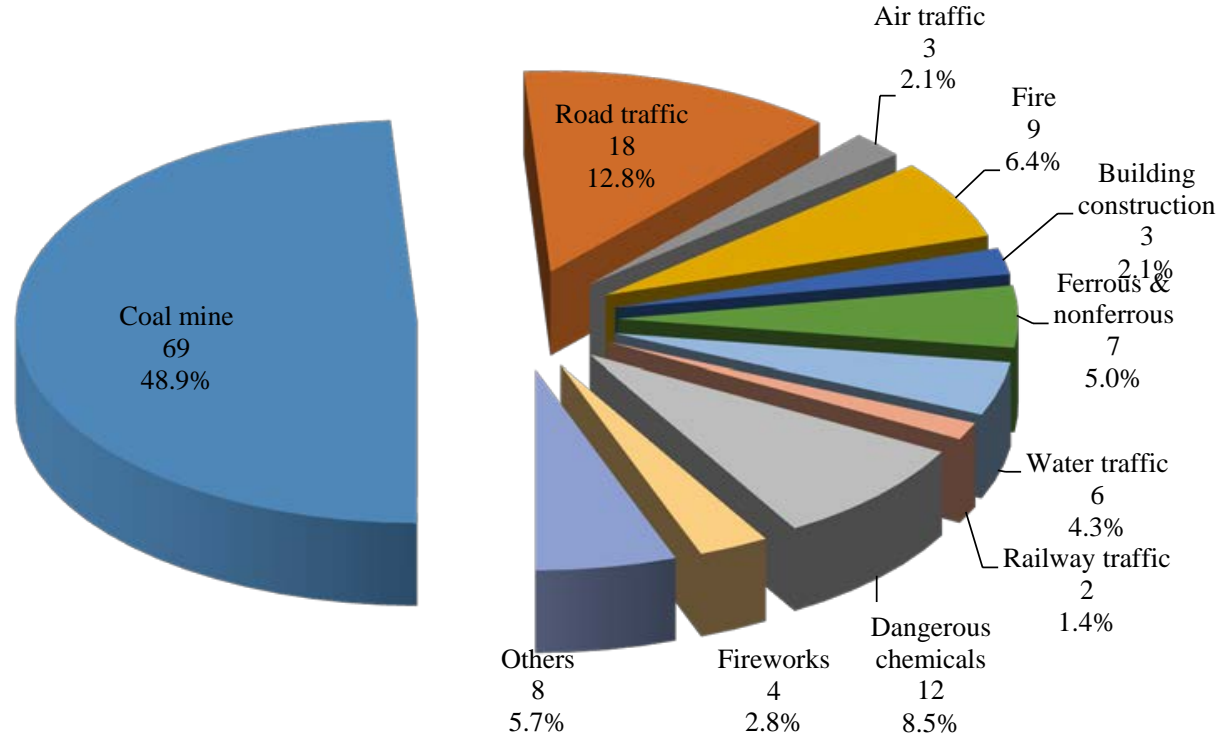

Number of Accidents

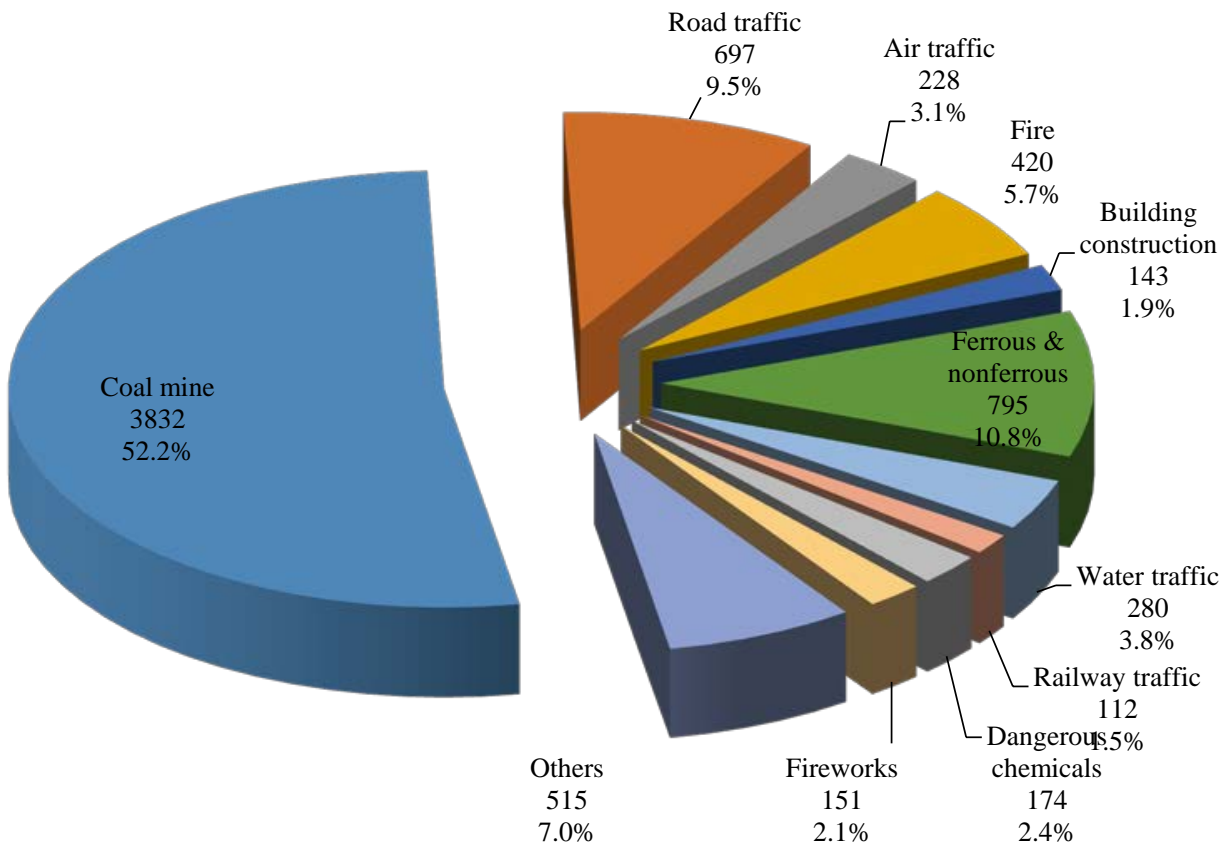

Number of Deaths

Fig. 6 Analysis on Extraordinarily Serious Accidents by Industrial Sector from 2001 to 2015 
As shown in the distribution of accidents in industrial sectors, extraordinarily serious accidents often occurred in some industrial sectors. From 2001 to 2015, coal mine caused 69 extraordinarily serious accidents and 3,832 deaths, accounting for $48.9 \%$ and $52.2 \%$ of total numbers in China respectively. In some years, the percentage had even exceeded $80 \%$, so special attention must be paid to the prevention of extraordinarily serious accidents in coal mine. Additionally, road traffic resulted in 18 extraordinarily serious accidents and 697 deaths, accounting for $12.8 \%$ and $9.5 \%$ of total numbers in China respectively. The extraordinarily serious accidents in such two industrial sectors took up more than 60\% of total number. The details are shown in Fig. 6.

(5) Extraordinarily serious accidents often occurred in main coal production areas
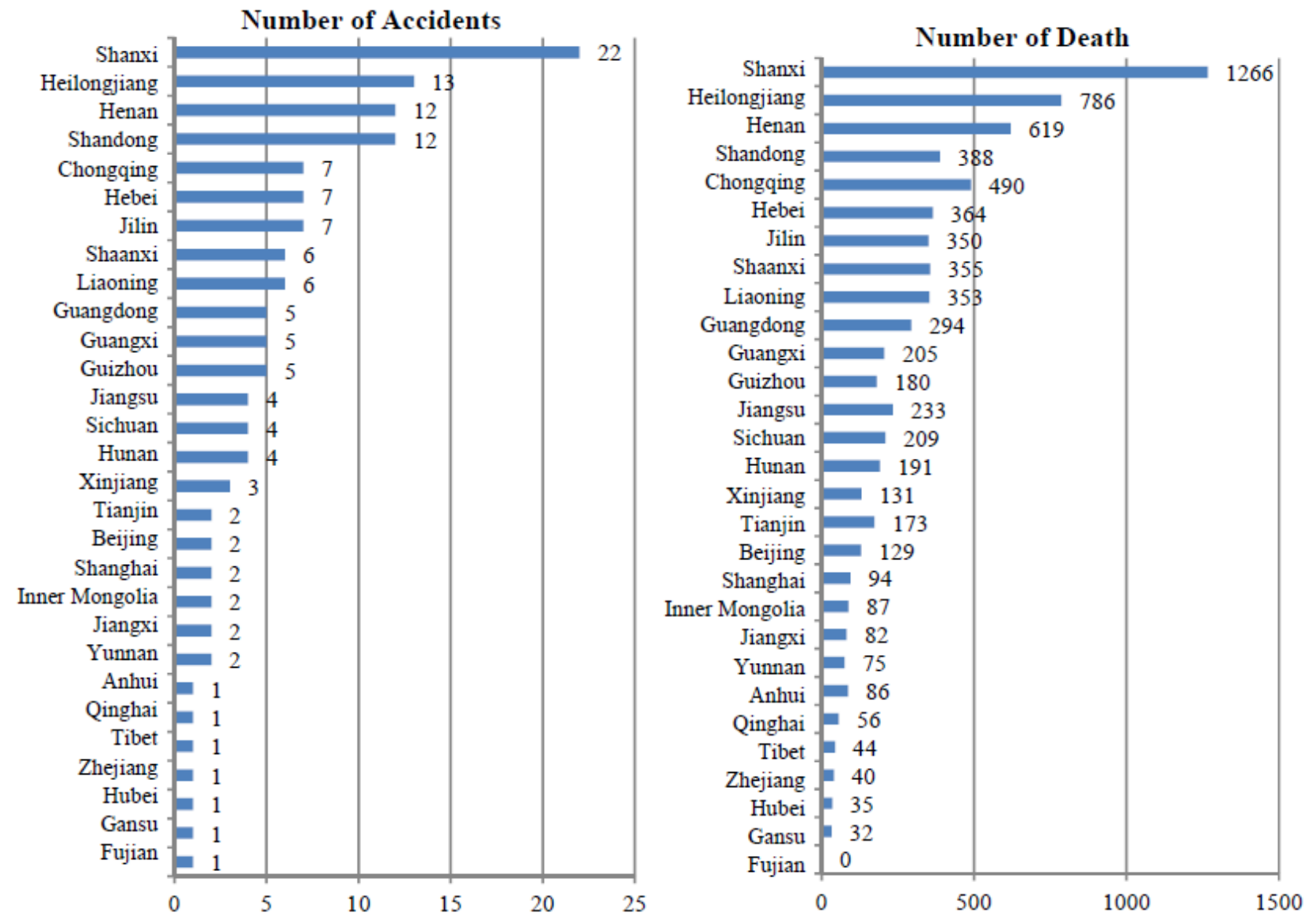

Fig. 7 Extraordinarily Serious Accidents by Region from 2001 to 2015

As shown in the regional distribution of accidents, there were 59 extraordinarily serious accidents and 3,059 deaths in 4 provinces for their large number of coal mines, that is, Shanxi, Heilongjiang, Henan and Sichuan from 2001 to 2015, which accounted for $41.8 \%$ and $41.6 \%$ of total numbers in China during the same period respectively. Among them, Shanxi had 22 accidents causing 1,266 deaths, accounting for $15.6 \%$ and $17.2 \%$ of total numbers in China during the same period respectively, while Heilongjiang had 13 accidents causing 786 deaths, accounting for $9.2 \%$ and $10.7 \%$ of total numbers in China during the same period respectively. The details are shown in Fig. 7.

\section{Conclusion}

The occurrence of extraordinarily serious accidents shows some obvious regularity for some reasons, so the regularity should be analyzed and generalize to determine the effective preventive and control measures in a focused manner. Obviously, extraordinarily serious accidents may occur in different time periods, frequently in some provinces, and often in such key industrial sectors as coal mine and road traffic. To control the extraordinarily serious accidents, efforts must be made in various aspects, e.g. improving the work safety responsibility system, enhancing the safety standards, and bettering the safety technical equipment and level, etc. 


\section{References}

[1] Zeng Mingrong et al. Evaluation on progress of carrying out national eleventh five-year program for work safety. Journal of Safety Science and Technology, 2011, 8:104-108.

[2] $\mathrm{Wu}$ Xin et al. Mid-term evaluation of progress in carrying out national twelfth five-year program for work safety. China Safety Science Journal, 2013, 23 (10): 145-151.

[3] Li Yizhong. Current development trend of and countermeasures for work safety in China. China Petroleum and Chemical Standard and Quality, 2007, 27 (5): 5-15.

[4] Ma Heng. Statistics and Analysis of Coal Mine Safety Accidents. Fuxin: Liaoning Technical University, 2012.

[5] Zhou Xihua, Zhong Meiduo, and Zhao Chaofeng. Statistical analysis of rules of extraordinary big accidents in China. World Sci-tech R\&D, 2011, 33 (12): 999-1001. 